\title{
The Mediating Effects of Self-Differentiation on the Relationship between Covert Narcissism of University Students and Relationship Addiction
}

\section{대학생의 내현적 자기애가 관계중독에 미치는 영향 : 자아 분화의 매개 효과}

Yunae Park ${ }^{1}$, Eunsil Kim²

박윤애 ${ }^{1}$, 김은실 ${ }^{2}$

${ }^{1}$ Student, Addiction Rehabilitation Counseling, Namseoul University Graduate, Korea, yunae0750@naver.com

${ }^{2}$ Professor, Child Welfare, Namseoul University, Korea, gender@hanmail.net

Corresponding author: Eunsil Kim

\begin{abstract}
The purpose of this study is to prove the mediating effect of Self-Differentiation on the relationship between Covert Narcissim and Relationship Addiction. This study was conducted on 400 University students living in Korea composed of 72 men and 328 women. The research tools were Covert Narcissism Scale (CNS), Relationship Addiction Questionnaire (RAQ-30), and Differentiation of Self Scale. The results of this study are as follows. On the other hand, covert narcissism showed positive correlation with relationship addiction, while, self-differentiation showed negative correlation with relationship addiction. As a result of verifying the mediating effect of self-differentiation in the relationship between covert narcissism and relationship addiction of University students, the higher the tendency of covert narcissism of University students, the lower the level of self-differentiation, and the higher the tendency of covert narcissism of University students, the higher the relationship addiction. In addition, self-differentiation was found to play a partial mediating role in the relationship between covert narcissism and relationship addiction of University students. As covert narcissism increased, selfdifferentiation decreased, and as the level of self-differentiation decreased, the tendency of relationship addiction increased. In other words, the higher covert narcissism, the more tendencies of relationship addiction and the lower level of self-differentiation. The stronger the tendency of covert narcissism of University students, the lower the ability to separate oneself and others, and the deeper the emotional convergence with others, the more likely they are to rely on others. The results of this study suggests that it is necessary to help establish an independent identity by promoting self-differentiation of university students in order to solve the difficulties of relationship among university students.
\end{abstract}

Keywords: University Students, Covert Narcissism, Relationship Addiction, Self-differentiation

요약: 본 연구의 목적은 대학생의 내현적 자기애, 관계중독, 자아 분화 간의 관계를 알아보고, 내현적 자기애와 관계중독과의 관계에서 자아 분화가 매개하는지를 알아보기 위함이다. 본

*This study is a revised and supplemented thesis for the first author's Master's degree (Namseoul University, 2020).

Received: March 19, 2021; 1st Review Result: May 06, 2021; 2nd Review Result: June 21, 2021

Accepted: July 31, 2021 
연구 대상자는 전국에 거주하고 있는 대학생 400명으로 남자는 72명, 여자는 328명이였으며, 연구 도구는 내현적 자기애척도(Covert Narcissism Scale: CNS), 관계중독척도(Relationship addiction Questionnaire: RAQ-30), 자아 분화척도(Differentiation of Self Scale) 사용하였다. 연구 결과, 대학생의 내현적 자기애와 자아 분화는 유의미한 부적 상관관계, 대학생의 내현적 자기애와 관계중독과는 유의미한 정적 상관관계, 대학생의 자아 분화는 관계중독과 유의미한 부적 상관관계를 확인할 수 있었다. 그리고 대학생의 내현적 자기애와 관계중독 간의 관계에서 자아 분화의 매개효과를 검증한 결과, 대학생의 내현적 자기애의 성향이 높을수록 자아 분화의 수준이 낮아지고, 대학생의 내현적 자기애의 성향이 높을수록 관계중독은 높아졌다. 또한, 자아 분화는 대학생의 내현적 자기애와 관계중독과의 관계에서 부분 매개 역할을 하는 것을 확인할 수 있었다. 내현적 자기애가 증가할수록 자아 분화는 감소하고, 자아 분화 수준이 낮을수록 관계중독 성향이 높아졌다. 즉, 내현적 자기애가 높을수록 관계중독의 성향을 보이며 자아 분화의 수준은 낮은 것이다. 대학생의 내현적 자기애의 성향이 강할수록 자신과 타인을 분리하는 능력이 낮아지고 타인과의 정서적 융합은 심화하여 타인에게 의존할 가능성이 높다고 할 수 있다. 본 연구의 의의는 대학생의 관계 어려움을 해결하기 위해서는 대학생의 자아 분화를 촉진하여 독립적 정체성의 확립을 도와주는 것이 필요하다는 것을 시사한다.

핵심어: 대학생, 내현적 자기애, 관계중독, 자아 분화

\section{1. 서론}

인간은 끓임없이 다른 사람을 마주하며 관계 안에서 살아가고, 이를 통해 정서적 친밀감을 경험하고자 하며 그 안에서 소속감과 안정감을 추구한다[1]. 인터넷과 SNS 의 발달과 보급으로 다양한 문화를 영위하는 사람들과 교류가 가능해짐으로 인하여 사람들 간의 관계가 양적으로 증가하였으며, 대면이 아닌 비대면으로도 손쉽게 새로운 관계를 형성하며 살아갈 수 있게 되었다. 그러나 관계양상 속에서 외로움을 느끼거나 깊이 있는 인간관계를 맺고 유지하는 데 어려움을 호소하는 사람들이 점차 늘어나는 추세이다. 더 나아가 인간관계에 강박적으로 집착하고, 타인과의 교류가 없으면 불안감을 느끼며, 자기의 감정을 솔직히 드러내지 못한 채 자신보다 상대의 요구를 우선시하는 ‘관계중독'에 빠진 현대인들이 늘고 있다.

$\operatorname{Martin}(1991)$ 은 관계중독을 특정한 사람이나 관계에 광적으로 집착하여 스스로 통제의 어려움을 느끼며 타인에게 의존적이고 강박적인 모습을 보이는 것이라고 말했다[2]. 관계중독에 빠진 사람들은 자신에게 부정적인 영향을 미치는 관계임을 인지하고 있음에도 불구하고 지속해서 그 관계를 유지하기 위한 애를 쓰며[3], 관계가 깨지는 것에 대한 지나친 두려움으로 인해 관계 유지를 위해서라면 모든 것을 희생하고, 상대방을 위해 무엇이든 하거나 포기하기도 하는 등 자신과 타인 간의 경계가 모호하거나 사라지기도 한다[4]. 이처럼 관계중독에 빠진 사람들은 겉으로 보기에는 끊임없는 대인관계 속에서 삶을 살아가는 것처럼 보이지만 실질적으로는 진정한 상호작용과 그로 인한 심리적 안정감을 얻지 못하는 관계를 맺고 있다. 또한, Schaeffer 와 McElhny(1997)은 잘못된 관계의 경험이 반복적으로 이루어지게 되면 타인과의 교류 없이 혼자 있는 느낌을 받거나 공허감, 고립감, 외로움 속에 빠지게 되며 내면에서는 지속적인 고통을 
경험하게 된다고 하였다. 심지어 고통을 잊기 위해서 또다시 관계에 몰두하며 계속해서 병리적인 관계에서 벗어나지 못 하는 행동을 보인다[5].

관계중독은 개인적, 환경적 요인에 의해서 영향을 받는데, 최근에 관계중독과 같은 대인관계의 문제에 영향을 미치는 성격 특성 요인으로 자기애(Narcissism)에 대한 관심이 증가하고 있다[6]. 자기애는 외현적 자기애와 내현적 자기애로 구분되는데, 관계중독은 특히 내현적 자기애와 관련이 많다는 연구들이 제시되고 있다[7-12]. 내현적 자기애(Covert Narcissism)는 스스로에 대한 확신이 부족하고 열등감과 자기 의심, 수줍음과 같은 내성적인 행동, 취약함, 자기비판을 가지며 현실적 좌절과 타인의 시선, 평가에 대한 민감성을 보인다. 윤성민과 신의천(2007)은 타인과의 관계 속에서 진심으로 다른 사람에게 의존하거나 다른 사람을 신뢰하지 못하는 모습을 보이며, 외적으로는 가까운 사람을 존중하는 듯 보이지만 내면적으로는 그 사람의 능력을 질투하고 평가를 절하하는 모습을 보이게 된다고 하였다.

관계중독에 영향을 주는 환경적 요인으로는 대인관계를 경험하고 배우는 1 차적인 집단인 원가족이 있다. 특히 부모와의 관계 경험은 내적 표상이 되어 추후의 사회적 관계 패턴의 원형이 되어 또래관계, 배우자관계, 대인관계에 영향을 미친다[13]. Bowen 은 부모와의 관계 경험은 나중에 대인관계에서 타인과 자신의 정체성을 유지하도록 돕는 자아 분화(Self-Differentiation)에도 영향을 준다고 하였다[14]. 자아 분화는 원래의 가족 안에서 공유하고 있는 문화나 가치의 융합으로부터 분리되어, 개인으로써 주체성을 가지고 다른 사람과의 깊고 성숙한 관계를 맺을 수 있으며, 타인과의 친밀한 관계를 유지함과 동시에 스스로 자율성과 독립성을 잃지 않고 자신한테 집중하여 온전히 자신의 모습으로 살아가는 정서적 균형 능력이다. 즉, 가족 구성원 내의 정서적인 융합과 결합에서 벗어나 자유를 느끼는 과정이라는 정의를 내릴 수 있으며 개인의 능력을 키워 나가며 개인의 인간적인 성숙도를 향상하는 개념이다[15]. 이처럼 내현적 자기애와 자아 분화는 관계중독에 빠진 사람들에게 매우 중요한 요인이라고 할 수 있다.

전 생애에 걸치는 발달과정 중에서 대학생들은 제한적이고 규범이 정해져 있는 체계적이고 압박이 존재하는 생활에서 벗어나 갑작스럽게 넓어진 관계의 폭을 경험하게 되면서 올바른 대인관계를 형성하는 과정에 있어서 정서적으로 혼란스러움을 경험하기도 한다[4]. 대학생들은 청소년기에 올바른 관계 형성 방법을 습득하지 못한 채 성장한 성인기 초기에 상대방에 대한 공감적 이해와 자신에 대한 통찰의 능력이 상대적으로 부족할 가능성이 있고, 관계중독과 같은 병리적인 대인관계에 빠질 위험성이 다른 성인에 비해 가능성이 크다[16]. 이 시기의 대학생은 스스로 자립할 수 있는 능력이 부족하며 관계 형성에 있어 미흡하고, 타인과 자신의 감정을 이해하는 데에 어려움을 느끼며 그로 인한 타인과의 상호작용에 문제가 발생할 가능성이 크다. 따라서 대학생들의 원만한 대인관계를 돕기 위해서는 대학생들이 경험하는 관계중독에 영향을 주는 변인 간의 관계를 알아볼 필요가 있다. 이에 본 연구에서는 대학생의 관계중독에 영향을 주는 내현적 자기애와 자아 분화의 관계를 알아보고자 한다.

\section{2. 연구 방법}

\section{1 연구 대상}

본 연구 대상자는 전국에 거주하고 있는 대학생 400 명을 대상으로 조사가 이루어졌다. 회수된 400 부 중 응답이 불성실한 자료 12 부를 제외하고, 총 388 부를 최종 분석에 
사용하였다. 남자는 68 명, 여자는 320명이며, 1학년은 182명, 2학년은 69명, 3학년은 54명, 4 학년은 75 명, 5 학년은 8 명이었다.

\section{2 연구 도구}

본 연구에서는 일반적 특성 6 문항, 내현적 자기애척도 45 문항, 관계중독 30 문항, 자아 분화 36 문항으로 총 117 문항의 자기 보고식 질문지를 사용하였다.

\subsection{1 내현적 자기애}

내현적 자기애 성향을 측정하기 위하여 Akhtar 와 Thomson(1982)의 '자기애적 성격장애의 임상적 특성, 내용을 기초로 강선희와 정남운(2002)이 비임상 집단을 대상으로 개발한 총 45 문항의 자기 보고형 질문지를 사용하였다. 내현적 자기애 척도는 5 개 하위요인인, ‘인정욕구/거대자기환상', ‘착취/자기중심성, ‘목표불안정', ‘과민/취약성', ‘소심/자신감부족'으로 구성되었다. 본 척도 문항은 5 점 Likert 식 척도로 총 점수는 45 점에서 225 점까지 분포되어 있으며, 점수가 높을수록 내현적 자기애 성향을 많이 가지고 있는 것으로 판단한다. 본 연구에서 신뢰도는 전체척도의 Cronbach's $\alpha .92$ 이고, 하위요인은 목표불안정 $\quad .92$, 인정욕구/거대자기환상 $\quad .78$, 착취/자기중심성 $\quad .81$, 과민/취약성 .82 , 소심/자신감부족 .80 로 나타났다.

\subsection{2 관계중독}

관계중독을 측정하기 위해, Peabody(2005) 기존의 관계중독 척도 타당화를 분석하는 총 40 문항 중 연구 대상자가 청소년기를 벗어나 성인기에 들어서는 대학생이라는 특성을 반영하여 동거와 비슷한 깊은 연애로 인하여 느낄 수 있는 감정이나 경험을 대상으로 한 질문 등 10 개의 질문을 제외하고 국내판 관계중독 설문지 RAQ-30으로 우상우(2014)가 재구성한 질문지를 사용하였다. 본 척도 문항은 5점 Likert식 척도로 검사 점수가 높을수록 관계중독 성향이 높음을 의미한다. 우상우(2014) 연구의 내적 합치도는 .90 이었다. 본 연구결과에서는 Cronbach's $\alpha$ 가 .93로 나타났다.

\subsection{3 자아 분화}

자아 분화를 측정하기 위해, Bowen 의 가족체계이론을 기반으로 제석봉(1989)이 개발한 자아 분화 척도를 사용하였다. 본 척도는 정서인지분화, 자아통합, 가족투사과정, 정서적단절, 가족퇴행 등 5 개의 하위요인으로 구성되었으며, 총 36 개 문항으로 이루어진 4 점 척도이다. 본 연구에서는 자아 분화 척도의 Cronbach's $\alpha$ 계수는 .88 로 나타났다.

\section{3 연구 절차}

본 연구는 2020 년 8 월 27 일부터 9 월 28 일까지 수도권, 강원도, 충청도, 경상도, 대구, 전라도, 제주도 등 각 지역의 거주 하는 대학생 약 400 명을 대상으로 설문조사를 실시하였다. 코로나-19 상황으로 학생들을 직접 만나 설문지를 전달하기 어려운 상황으로, 온라인설문지를 배부하여 수집하였다. SNS 를 통해 참여 요청 및 연구 진행 목적을 설명하고, 연구에 동의를 한 학생들에게 설문을 요청하여 회수하였다. 회수된 설문지 총 400 부 중 무작위로 응답한 것이라고 판단되거나 불성실한 응답의 가능성이 보인 설문지 12 부를 제외한 총 388 부를 최종 연구 분석에 사용하였다. 


\section{4 자료 분석}

본 연구에서 수집된 자료는 SPSS Win 23.0 통계프로그램을 이용하여 분석하였다. 변인들의 기술통계치 확인을 위해서 백분율과 빈도, 왜도와 첨도를 알아보았으며, 신뢰도 확인을 위해서 Cronbach's $\alpha$ 값을 알아보았다. 내현적 자기애, 관계중독, 자아 분화 간의 상관관계를 알아보기 위해서 Pearson 의 상관분석을 시행하였다. 내현적 자기애가 관계중독에 미치는 영향에서 자아 분화의 매개효과를 분석하기 위해서, Baron 과 Kenny 의 방법을 근거하여 다중회귀분석을 시행하였다. 그리고 Sobel Z-test 를 통해 매개모형의 유의성을 확인하였다.

\section{3. 연구 결과}

\section{1 변인들의 기술통계}

본 연구의 정규성 검증을 위해 변인의 평균, 표준편차 외에도 왜도(skew)와 첨도(kurtosis)를 확인하였다. 분석 결과 [표 1]과 같이 모든 변인의 왜도와 첨도는 유의수준 .05 에서 모든 기준을 만족하는 것으로 나타났다. 또한 각 요인의 하위요인에서도 왜도의 경우 절대값이 1 을 넘지 않으며, 첨도에서도 1 을 넘지 않은 것으로 나타나 모든 측정변수의 정상성을 만족하는 것으로 나타났다. 이에 본 연구의 측정 도구 검증 및 분석에 문제가 없는 것을 확인하였다.

[표 1] 기술통계치

[Table 1] Technical Statistics $(\mathrm{N}=388)$

\begin{tabular}{c|c|c|c|c|c|c|c}
\hline 변인 & Min & Max & $M$ & $S D$ & 왜도 & 첨도 & Cronbach's \\
\hline 내현적 자기애 & 47 & 194 & 125.33 & 22.84 & -.336 & .530 & .92 \\
\hline 목표불안정 & 9 & 45 & 25.04 & 7.82 & -.008 & -.494 & .92 \\
\hline $\begin{array}{c}\text { 인정욕구/ } \\
\text { 거대자기환상 }\end{array}$ & 9 & 45 & 27.74 & 5.61 & -.295 & .658 & .78 \\
\hline 착취/자기중심성 & 9 & 40 & 20.26 & 5.84 & .468 & .244 & .81 \\
\hline 과민/취약성 & 10 & 46 & 27.71 & 7.08 & -.077 & -.135 & .82 \\
\hline 소심/자신감부족 & 9 & 40 & 24.58 & 5.73 & -.331 & -.121 & .80 \\
\hline 관계중독 & 32 & 122 & 63.78 & 17.37 & .568 & .175 & .91 \\
\hline 자아 분화 & 67 & 133 & 104.02 & 13.50 & -.386 & -.269 & .46 \\
\hline 정서인지분화 & 71 & 28 & 20.58 & 3.27 & -.175 & -.425 & .68 \\
\hline
\end{tabular}




\begin{tabular}{l|c|c|c|c|c|c|c}
\hline 가족투사 & 6 & 24 & 19.43 & 3.76 & -.659 & -.036 & .85 \\
\hline 정서적단절 & 6 & 24 & 16.19 & 4.22 & -.373 & -.347 & .83 \\
\hline 가족퇴행 & 11 & 44 & 32.71 & 6.97 & -.614 & .021 & .91 \\
\hline
\end{tabular}

\section{2 내현적 자기애, 관계중독, 자아 분화 간의 상관관계}

본 연구의 주요 변인들 상관관계를 알기 위해 Pearson 의 상관분석을 시행하였다. 연구 결과는 아래의 [표 2]에 나타나 있다. 그 결과, 대학생의 내현적 자기애와 자아 분화 $(\mathrm{r}=$ $-.55, \mathrm{p}<.001)$ 는 유의미한 부적 상관관계를 보였고, 대학생의 내현적 자기애와 관계중독 $(\mathrm{r}$ $=.48, \mathrm{p}<.001)$ 은 유의미한 정적 상관관계를 보였다. 대학생의 자아 분화는 관계중독 $(\mathrm{r}=-.37$, $\mathrm{p}<.001)$ 과 유의미한 부적 상관관계를 보이는 것을 확인하였다.

[표 2] 내현적 자기애, 관계중독, 자아 분화 간의 상관관계

[Table 2] The relationship between Covert Narcissism, Relationship Addiction and Self-Differentiation $(\mathrm{N}=388)$

\begin{tabular}{c|c|c}
\hline & 관계중독 & 자아 분화 \\
\hline 내현적 자기애 & $.48^{* *}$ & $-.55^{* *}$ \\
\hline 자아 분화 & $-.37^{* *}$ & \\
\hline
\end{tabular}

${ }^{*} p<.05 .{ }^{* *} p<.01$.

\section{3 내현적 자기애가 관계중독에 미치는 영향에 대한 자아 분화의 매개효과}

대학생의 내현적 자기애와 관계중독 간의 관계에서 자아 분화의 매개효과 검증을 위해, 위계적 회귀분석을 실시한 결과는 [표 3]과 같다.

대학생의 내현적 자기애와 관계중독 간의 관계에서 자아 분화가 매개 역할을 하는가를 분석한 결과, 1 단계에서 대학생의 내현적 자기애가 자아 분화에 유의한 부적 영향을 미치는 것으로 보였다 $(\beta=-.55, \mathrm{p}<.001)$. 즉, 대학생의 내현적 자기애의 성향이 높을수록 자아 분화의 수준이 낮아진다고 해석할 수 있다. 2 단계, 대학생의 내현적 자기애가 관계중독에 유의한 정적 영향을 미치는 것으로 보였다 $(\beta=.48, \mathrm{p}<.001)$. 즉, 대학생의 내현적 자기애의 성향이 높을수록 관계중독이 높아진다고 해석할 수 있다. 마지막 3 단계에서 대학생의 내현적 자기애와 자아 분화가 관계중독에 미치는 영향력을 보았을 때, 매개변수인 자아 분화는 관계중독에 통계적으로 유의한 수준에서 부적인 영향을 미치고 있었다 $(\beta=-.15, \mathrm{p}<.01)$. 또 독립변수인 내현적 자기애는 종속변수인 관계중독에 통계적으로 유의한 정적인 영향 $(\beta=.40, \mathrm{p}<.001)$ 을 미쳤다. 2 단계에서 내현적 자기애인 독립변수가 종속변수에 미치는 영향력(내현적 자기애, $\beta=.48$ )보다 3 단계에서의 영향력(내현적 자기애, $\beta=.40$ )이 낮게 나타났으므로 자아 분화는 대학생의 내현적 자기애와 관계중독 간의 관계에서 부분 매개하는 것을 확인할 수 있었다.

대학생의 내현적 자기애와 관계중독의 관계에서 자아 분화의 매개 경로가 통계적으로 
유의한지를 검증하기 위해 Soble test 검증 결과 자아 분화가 관계중독에 유의한 영향을 미치는 것으로 보였다 $(B=-.15, p<.01)$. Sobel Z- test를 실시한 결과 Sobel Z 값은 2.81 로 $p<$. 01의 수준에서 유의하게 나타났다. Baron 와 Kenny(1986)는 Sobel Z test의 결과값이 +1.96 보다 크거나, -1.96 보다 작으면 매개효과가 유의미하다고 판정한다. 즉, 내현적 자기애가 관계중독에 직접적으로 영향을 미치기도 하지만, 내현적 자기애가 관계중독에 자아 분화는 부분적으로 매개하는 것을 확인하였다.

[표 3] 대학생의 내현적 자기애가 관계중독에 미치는 영향: 자아 분화의 매개효과

[Table 3] The Mediating Effects of Self-Differentiation on the Relationship between Covert Narcissism of University Students and Relationship Addiction $(\mathrm{N}=388)$

\begin{tabular}{|c|c|c|c|c|}
\hline 단계 & 변인 & $\beta$ & $R^{2}$ & $F$ \\
\hline 1. 독립 $\rightarrow$ 매개 & 내현적 자기애 $\rightarrow$ 자아 분화 & $-.55^{* * *}$ & .31 & $169.42^{* * *}$ \\
\hline 2. 독립 $\rightarrow$ 종속 & 내현적 자기애 $\rightarrow$ 관계중독 & $.48^{* * *}$ & .23 & $115.02^{* * *}$ \\
\hline \multirow{2}{*}{$\begin{array}{c}\text { 3. 독립 } \rightarrow \text { 종속 } \\
\text { 매개 } \rightarrow \text { 종속 }\end{array}$} & 내현적 자기애 $\rightarrow$ 관계중독 & $.40^{* * *}$ & \multirow{2}{*}{.25} & \multirow{2}{*}{$62.73^{* * *}$} \\
\hline & 자아 분화 $\rightarrow$ 관계중독 & $-.15^{* *}$ & & \\
\hline
\end{tabular}

\section{4. 논의}

본 연구의 목적은 대학생의 내현적 자기애와 자아 분화가 관계중독에 어떠한 영향을 미치는지 파악하고 그 의미를 탐구하고자 하였다. 이를 위해 내현적 자기애와 관계중독의 매개 변인인 자아 분화를 선정하여 상관관계를 파악하였으며, 매개 변인이 유의미한 차이를 보이는지 검증하였다.

본 연구를 통해 나타난 주요한 결과를 논의하면 다음과 같다.

첫 번째, 내현적 자기애는 자아 분화와 통계적으로 유의미한 부적 상관관계를 보였으며, 내현적 자기애는 관계중독과 유의미한 정적 상관관계를 보였다. 자아 분화는 관계중독과 유의미한 부적 상관을 보였다. 즉, 자아 분화의 수준이 낮을수록 내현적 자기애의 성향이 높으며, 내현적 자기애가 높을수록 가족관계의 융합이 단절되는 것에 어려움이 있음을 보여주고 있다. 이는 대학생들이 내현적 자기애가 높을수록 독립적이고 자주적인 결정을 하는 데에 어려움을 느낀다는 것을 시사한다. 주관적인 감정과 객관적인 판단 과정에서 조화롭지 못한 개인은 자신의 정체성을 확보하는 것에 어려움을 느끼며 자아 분화가 이루어지지 않아 개인 자체는 물론 개인을 둘러싸고 있는 환경에 대한 지각이 어려운 특징이 있는데 이는 내현적 자기애 성향이 있는 사람들은 내성적이고 타인의 주장에 과도하게 집착하는 경향을 보이는 것을 설명할 수 있다. 
두 번째, 본 연구에서는 대학생의 내현적 자기애가 관계중독의 영향을 보았을 때, 내현적 자기애가 관계중독에 직접적인 영향을 미치는 것으로 확인하였다. 내현적 자기애의 성향이 높은 사람들은 자아존중감이 약하기 때문에, 자신의 이러한 부족한 자아존중감을 타인으로부터 인정받는 모습을 통해 충족하려는 경향을 보인다[7]고 할 수 있다. 이는 내현적 자기애 성향이 있는 사람들은 끊임없이 타인의 시선에 민감하게 반응하며 자신감이 결여되어 대인관계에서 의존과 집착, 그리고 타인의 평가에 민감함을 시사한다. 이러한 결과는 내현적 자기애 성향이 있는 사람들의 내면에 존재하는 결핍을 타인을 통해 충족시키려고 하고 욕구를 해소하려는 모습을 설명하는 지표로 활용될 수 있다. 특히 내현적 자기애 수준이 높을수록 관계중독의 성향이 강하다는 것으로 나타났는데 이는 자신에 대한 신뢰와 자존감이 낮을수록 타인에게 의존하고 자신에게 해로운 결과를 초래하는 관계임에도 불구하고 무조건 수용하고 헌신하는 태도를 보인다는 것을 알 수 있다. 이는 관계중독에서 벗어나기 위해서는 자존감을 향상해서 내현적 자기애를 벗어날 수 있도록 돕는 접근이 필요함을 시사한다.

마지막으로, 본 연구의 결과, 내현적 자기애가 관계중독에 미치는 영향에서 자아 분화가 부분 매개 효과가 있었다. 즉, 내현적 자기애가 증가할수록 자아 분화가 감소하고, 자아 분화 수준이 낮을수록 관계중독 성향이 높다고 할 수 있다. 이는 자아 분화가 수준이 높은 사람의 경우 사고와 감정이 균형을 이루어 강한 정서를 갖더라도 정서적 충동에 저항할 수 있는 자제력과 객관성을 가지고 있다[17]. 반면에 자아 분화 수준이 낮은 경우, 주관적 감정에서 객관적 사고를 분리하기 어렵다. 그래서 자신과 외부세계를 지각하는 데 객관성이 결여되어 있으며, 본능적인 충동에 따라 반응할 가능성이 높다. 이는 대학생의 대인관계에서 자아 분화 수준을 높여서 자아 정체감을 높여 타인과 쉽게 융합되지 않으며, 자신의 의견과 감정을 독립적으로 표현할 수 있도록[13] 돕는 접근들이 필요함을 시사한다.

본 연구결과를 살펴보면, 대학생의 내현적 자기애의 성향이 강할수록 자신과 타인을 분리하는 능력이 낮아지고 타인과의 정서적 융합이 심화하여 타인에게 의존할 가능성이 높다. 이러한 경향으로 인해 대학생들은 다른 성인들에 비해 올바른 관계를 형성하는 데에 어려움을 느낀다[16]. 또한, 자신에게 해가 되는 관계임을 깨닫고 벗어나고자 노력하지만 관계를 끊어내는 것에 어려운 모습을 보일 수도 있다. 이를 해소하기 위해서는 상담 과정에서 친밀한 관계의 어려움을 겪는 내담자에게 자아 분화와 독립적인 정체성의 확립을 도와주는 것이 필요하다.

본 연구의 후속 연구를 위한 제언은 다음과 같다.

첫 번째, 본 연구의 인구통계학적 결과를 살펴보면 여학생의 수와 1 학년이 상대적으로 높은 비율을 차지하고 있어 연구 결과를 일반화하는 데는 어려움이 따른다. 따라서 학년별 남녀 대학생의 비율을 비슷한 표집으로 조사하여 자아 분화의 수준이 대학생의 내현적 자기애와 관계중독에 미치는 영향을 살펴보는 것이 필요하다.

두 번째, 본 연구는 자기 보고식 설문지를 이용했기 때문에, 응답자들의 방어적 태도가 반영되거나 사회적인 바람직성에 근거하여 정직하게 응답하지 않았을 경우가 존재한다. 불성실한 응답으로 인하여 연구의 결과가 편향되었을 가능성이 함으로 추후 진행될 연구에서는 자기 보고식 설문지 외에도 다양한 연구 방법을 이용하여 반복적으로 검증하는 것이 필요하다.

세 번째, 본 연구는 횡단 연구로써 자아 분화의 정도에 따른 대학생의 내현적 자기애와 관계중독의 정도를 동시에 측정하였다. 횡단 연구의 특성상 각 변인 간의 
인과관계를 파악하기 위한 정확한 정보를 제공하는 것에 어려움이 따르므로 추후 진행될 연구에서는 종단연구를 통해 더욱 정확하고 자세하게 인과관계를 파악하고 자아 분화의 매개효과를 살펴보는 것이 필요하다.

마지막으로, 본 연구에서는 대학생의 내현적 자기애가 관계중독에 미치는 영향에서 자아 분화가 매개하는지를 살펴보았으므로, 추후 진행될 연구에서는 가정의 형태나 가족 내 출생순위, 연애 경험 등과 같은 특성에 따라 연구 결과에 변화가 있는지 통제 변인을 통해 살펴보는 것이 필요하다.

\section{References}

[1] Sun Mi Chi, The effects of parenting attitudes perceived by college students on relationship addiction : focusing on the mediating effects of abandonment schema, Hanyang University Graduate School, Master's Thesis, (2019)

[2] G. Martin,When Good Things Become Addictions (The Recovery bookshelf), Victor Books, (1991)

[3] Ji Hong Lee, The influence of self-differentiation level on relationship addiction: the mediating effects of basic psychological needs, Catholic University Graduate School, Master's Thesis, (2015)

[4] Bireda, R. Martha, Love Addiction : A Guide to Emotional Independence, Blue Ocean Press, (2017)

[5] Eun Ji Ko, The effect of insecure adult attachment on relationship addiction in university students : the mediating effect of self-concept clarity and soothing ability, Catholic University Graduate School, Master's Thesis, (2018)

[6] Sung-Joo Kim, Young-Soon Lee, The Relationship between Covert Narcissism and Social Anxiety in College Students: The mediating effects of Evaluative Concerns Perfectionism and Fear of Negative Evaluation and Internalized Shame, Korean Journal of Counseling, (2015), Vol.16, No.1, pp.199-216, DOI: 10.15703/kjc.16.1.201502.199

[7] Yiseul Kim, Hyeokcheol Kwon, Mediating Effect of Covert Narcissism in the Relation of Overprotective Parenting and Relationship Addiction, The Korean Journal of Rehabilitation Psychology, (2015), Vol.22, No.3, pp.517-530, UCI: G704-SER000009521.2015.22.3.007

[8] Yeon-Ji Jo, Relationship between Covert Narcissism and Relation Addiction in the University students: Focused on the Mediating Effect of Separation-individuation and Self-concept, Kwanwoon University Graduate School, Master's Thesis, (2016)

[9] Se-Kwang Kim, Hye-Young Hong, The Influence of Covert Narcissism on the Relation Addiction: Mediating Effect of Emotion Dysregulation and Perceived Social Support, The Journal of the Korea Contents Association, (2018), Vol.18, No.8, pp.392-407, DOI: https://doi.org/10.5392/JKCA.2018.18.08.392

[10] Lee Su Jeong, The effect of Covert Narcissism and Rejection Sensitivity of unmarried men and women on relationship addiction, Dongguk University Graduate School, Master's Thesis, (2017)

[11] Hye-Rim Bae, Suk Kyung Nam, The Gender Differences in the Mediating Effect of Covert Narcissism on the Relationship between Personality Traits and Relationship Addiction, Korea Journal of Counseling, (2019), Vol.20, No.2, pp.171-190, DOI: 10.15703/kjc.20.2.201904.171

[12] Seulki Baek, The Effect of Covert Narcissism of Unmarried Adults on Relationship Addiction: The Mediating Effect of Self-Differentiation, Myongji University Graduate School, Master's Thesis, (2020)

[13] Gyoung Mi Cho, The influence self-differentiation on self-esteem, and relationship addiction of early adulthood: gender's moderated mediation effect, Honggik University Graduate School, Master's Thesis, (2016)

[14] M. R. Bowen, Family therapy in clinical practice, Jason Aronson, $\left(1^{\text {st }}\right), 1993$, (first published 1978)

[15] Mun-ja Jung, Hye-jung Jung, Sun-hye Lee, Yeong-ju Jeon, FOUNDATIONS OF FAMILY THERAPY, Hakjisa, (2018)

[16] Ji Won Lee, Ki Hak Lee, The Influence of Insecure Attachment and Psychological Distress on Relationship Addiction: Testing the Moderated Mediating Effect of Support-seeking Emotion Regulation Style, Korean Journal of Counseling 
The Mediating Effects of Self-Differentiation on the Relationship between Covert Narcissism of University Students and Relationship Addiction

And Psychotherapy, (2014), Vol.26, No.1, pp.65-95, UCI: G704-000523.2014.26.1.002

[17] Seon Hwa Lee, Effects of Covert Narcissism and Ego-Resiliency on their Relationship Problems in University Students, Dongguk University Graduate School, Master's Thesis, (2015) 